\title{
Risas en la comodidad del hogar Un análisis de las comedias para adultos realizadas para el mercado del video hogareño en Argentina hacia fines de la década de 1980 y comienzos de 1990
}

\author{
Fabio Nicolás Fidanza
}

Recibido: 30.10.2020 — Aceptado: 28.11.2020

\section{Titre / Title/ Titolo}

Rires dans le confort de la maison. Une analyse des comédies pour adultes réalisées pour le marché du vidéo domestique en Argentine à la fin des années 80 et au début des années 90

Laughter in the Comfort of Home. An Analysis of the Adult Comedies Made for the Video Home Market in the late 1980's and the early 1990's in Argentina Risate nel comfort domestico. Un'analisi delle commedie per adulti realizzate per il mercato del video domestico in Argentina alla fine degli anni '80 e all'inizio degli anni ' 90

\section{Resumen / Résumé / Abstract / Riassunto}

En una serie de breves comentarios, Jesús Martín-Barbero (1987), postula lo cómico, junto con el melodrama, como una de las matrices de la cultura popular latinoamericana. Esta matriz cultural fue reelaborada por distintas disciplinas entre las que se destaca el cine. Cuando este la incorpora, y la reformula, da vida a diversas variantes entre las que se encuentra un tipo de comedia, centrada en lo sexual, que logró convertirse en uno de los subgéneros más populares de toda Latinoamérica. En la Argentina esta vertiente fue desde sus inicios una de las producciones cinematográficas más exitosas. Este modo, que emergió en los sesenta, continuó produciéndose hasta fines de los años ochenta y comienzos de los noventa cuando abandona los cines nacionales. Sin embargo, lejos de desaparecer encuentra refugio en el campo del video hogareño. Partiendo de estas consideraciones, la intención de este trabajo es abordar el desembarco del cine picaresco en el campo del video con el fin de analizar las continuidades y las rupturas que se produjeron en el traspaso a un nuevo medio, las reformulaciones que llevó a cabo de elementos de otras producciones con características similares (programas cómicos televisivos, el «Teatro de la Calle Corrientes») y los vínculos que estableció con otros géneros de la industria del video local como el video concert.

Dans une série de brefs commentaires, Jesús Martín-Barbero (1987) postule la comédie, avec le mélodrame, comme l'une des matrices de la culture populaire latino-américaine. Cette matrice culturelle a été retravaillée par différentes disciplines, parmi lesquelles le cinéma se démarque. Lorsqu'il l'incorpore et le reformule, il donne vie à diverses variantes parmi lesquelles un type de comédie, centré sur le sexuel, qui a réussi à devenir l'un des sous-genres les plus populaires de toute l'Amérique latine. En Argentine, cet aspect a été dès le début l'une des productions cinématographiques les plus réussies. Ce mode, apparu dans les années 1960, a continué à être produit jusqu'à la fin des années 1980 et au début des années 1990, lorsqu'il a quitté les cinémas nationaux. Pourtant, loin de disparaitre, il trouve refuge dans le domaine de la vidéo domestique. À partir de ces considérations, l'intention de ce travail est d'aborder l'atterrissage du cinéma picaresque dans le domaine de la vidéo afin d'analyser les continuités et les ruptures survenues dans le transfert vers un nouveau support, les reformulations qu'elle a effectuées d'éléments d'autres productions présentant des caractéristiques similaires (émissions de télévision comiques, le «Teatro de la Calle Corrientes») et les liens qu'elle a établis avec d'autres genres de l'industrie vidéo locale comme le concert vidéo.

In a series of brief comments, Jesús Martín-Barbero (1987), posits comedy, along with melodrama, as matrix of Latin American popular culture. This cultural matrix was reworked by different disciplines, among which 
cinema stands out. When the movie industry incorporates it, reformulating it, it gives birth to different variants among which a type of comedy, focused on sex, managed to become one of the most popular subgenres in all Latin America. In Argentina, this type of comedy was one of the most successful film productions since its beginning. Said kind of comedy, which emerged in the 1960s, continued to be produced until the late $1980 \mathrm{~s}$ and early 1990s when it abandonded the national movie theaters. However, far from disappearing, it found shelter in the home video market. Based on these considerations, the intention of this work is to address the landing of picaresque comedy into the home video market in order to analyze the continuities and the ruptures that occurred in the passage to a new media, the reformulations of elements from other productions with similar characteristics (television comic programs, the «Teatro de la Calle Corrientes») that was carried out, and the links established with other genres of the local video industry such as the video concert.

In una serie di brevi commenti, Jesús Martín-Barbero (1987), postula la commedia, insieme al melodramma, come una delle matrici della cultura popolare latinoamericana. Questa matrice culturale è stata rielaborata da diverse discipline, tra le quali spicca il cinema. Quando quest'ultimo lo incorpora, e lo riformula, dà vita a diverse varianti, tra cui un tipo di commedia, incentrata sul sesso, che è riuscita a diventare uno dei sottogeneri più popolari di tutta l'America Latina. In Argentina, questa variante è stata una delle produzioni cinematografiche di maggior successo sin dal primo momento. Tale modalità, emersa negli anni ' 60 , continuò ad essere prodotta fino alla fine degli anni ' 80 e all'inizio degli anni ' 90 , quando abbandonó i cinema nazionali. Tuttavia, lungi dallo scomparire, ha trovato rifugio nel campo del video domestico. Sulla base di queste considerazioni, l'intento di questo lavoro è quello di trattare lo sbarco del cinema picaresco nell'ambito del video domestico per analizzare le continuità e le rotture che si sono verificate nel passaggio a una nuova tecnologia, le riformulazioni che ha effettuato di elementi di altre produzioni con caratteristiche simili (programmi di commedie televisive, il «Teatro de la Calle Corrientes») e i legami che ha stabilito con altri generi dell'industria video locale come il video concerto.

\section{Palabras clave I Mots-clé $I$ Key words /Parole chiave}

Comedia, cine, video, intermedialidad, géneros cinematográficos.

Comédie, cinéma, vidéo, intermédialité, genres cinématographiques.

Comedy, cinema, video, intermediality, film genres.

Commedia, cinema, video, intermedialità, generi cinematografici.
Jesús Martín-Barbero señala que existen una serie de matrices culturales constitutivas de la cultura popularmasiva latinoamericana que, dada su fuerte capacidad de interpelar al público de sectores populares, tienen la particularidad de poder ser reformuladas dando vida a nuevas producciones. Para este autor, la matriz que atraviesa gran parte de la cultura popular y masiva de la región es el melodrama. Sin embargo, en una serie de breves comentarios postula «lo cómico como la otra vertiente de la matriz popular» (130). Afirma que los cómicos populares han interpelado históricamente a un público plebeyo que podía verse reflejado en los antihéroes torpes y grotescos que, con su lenguaje burdo y soez, se burlaban de la corrección y de los buenos modales de las clases dominantes. Esta segunda matriz cultural fue reelaborada por distintas disciplinas creando narrativas masivas que circularon por distintos medios de comunicación y por diversas producciones artísticas. Cuando el cine la incorpora, y la reformula, da vida a diversas variantes entre las que se encuentra un tipo de comedia centrada en lo sexual que logró convertirse en uno de los subgéneros más populares de toda Latinoamérica.

En Brasil fueron conocidas como pornochanchadas, un término despectivo que la crítica local le puso debido al alto contenido sexual que primaba en ellas, y en México como sexycomedias o «cine de ficheras», nombres que también dejan en claro que lo sexual tenía un peso importante en estas películas. En la Argentina, se las llamó comedias picarescas, y fueron desde sus inicios una de las producciones más exitosas del cine argentino. Si bien cada cinematografía le imprimió su sello propio, existieron una serie de rasgos comunes en estas producciones. Este tipo de comedia comenzó a producirse en momentos en los que la industria se encontraba en crisis y necesitaba tanto ahorrar costos como producir éxitos que la sacaran del estancamiento en el que se estaba. Es por ello que estas películas compartieron un modo de producción similar: presupuesto reducido y pocas semanas de rodaje con el fin de explotar el producto lo más rápido posible. A su vez compartieron temas, espacios, personajes y estructuras narrativas. Fueron protagonizadas por comediantes populares y por actrices y vedetes cuya 
escultural belleza funcionaba como un atractivo para el público masculino. Sus comienzos pueden remontarse a la década del sesenta y setenta, y su productividad se extendió hasta fines de los años ochenta y principios de los noventa. ${ }^{1}$ Sin embargo, lejos de desaparecer, en Argentina este modo encontró refugio en el campo del video, un espacio que, hacia el final de la década del ochenta, emergió como un ámbito propicio para continuar desarrollando esta modalidad cómica.

Partiendo de estas consideraciones, la intención de este trabajo es abordar el desembarco del cine de género picaresco en el campo del video con el fin de analizar las continuidades y las rupturas que se produjeron en el traspaso a un nuevo formato. Para pensar el devenir de la picaresca en el audiovisual argentino consideramos que puede ser útil la propuesta de Rick Altman (2000) en relación con los ciclos de los géneros cinematográficos. Para este autor los géneros no son estáticos ni permanecen inmutables, sino que, por el contrario, son el resultado de un proceso de transformación continuo que se da como resultado de las mutaciones en las demandas y gustos del público y de las necesidades de los estudios y de las productoras. Cuando una variante del género fue explotada al máximo se da el cierre de un ciclo. A partir del agregado de nuevos materiales se da vida a nuevos ciclos para continuar con la explotación. Es posible pensar entonces que hacia fines de los ochenta, en el ámbito de la comedia cinematográfica argentina, se produjo el cierre de un ciclo de este modo cómico, para luego iniciar uno nuevo en el campo del video. El desarrollo de esta versión de la picaresca no debe ser entendido como una mera adaptación a otro dispositivo ${ }^{2}$ sino como un

\footnotetext{
Sobre pornochanchada véase Camarero, 2017 y Kessler, 2009. Sobre sexycomedias véase Lemus Martínez, 2015 y Ramírez Ferreiro, 2017.

Siguiendo la propuesta de Gustavo Galuppo (2012) entendemos el video como un dispositivo tecnológico, como una tecnología de registro de imágenes, cuyo uso no es unívoco sino, por el contrario, diverso. A grandes rasgos podemos decir que su empleo en el campo del audiovisual transita entre dos polos. Uno de ellos, el polo artístico, buscó expandir las posibilidades expresivas del dispositivo por medio de la experimentación con las herramientas que brindan las cámaras de video. El otro, un polo comercial, que utilizó las novedades que el dispositivo introdujo con el fin de revitalizar las fórmulas y los formatos estandarizados que el cine y la televisión explotan. En este artículo nos concentraremos en el análisis de producciones que pueden pensarse como parte del segundo grupo.
}

fenómeno con características intermediales. Siguiendo a Rajewsky $(2005,51)$ entendemos que lo intermedial está dado por un proceso de hibridación de elementos de distintos medios. La producción directo a video, en tanto campo en construcción, recurrió a la combinación de recursos temáticos y narrativos de otros medios con mayor desarrollo como lo eran el cine, la televisión y el teatro. Esta nueva picaresca reconfiguró narrativas, temas y formas de representación de la versión cinematográfica y las combinó con mecanismos de otros medios en los que se desarrollaban géneros similares, como la televisión y el teatro.

Geoff King (2002) señala que la comedia debe ser pensada en relación con sus contextos políticos, económicos y culturales. Es por ello que para comprender las transformaciones que una matriz cultural, como lo es la comedia picaresca, sufre en el medio local en su traspaso a un nuevo dispositivo, es necesario tener en cuenta una serie de factores relacionados tanto con el campo de la producción como de la recepción (Martín-Barbero, 1987). Es decir que para comprender acabadamente el derrotero de este género debemos prestar especial atención a la situación de la industria audiovisual en el país y a los cambios producidos en los hábitos de consumo de los espectadores. Para poder dar cuenta de estas transformaciones, analizaremos en primer lugar la situación económica del país y de la industria audiovisual en los últimos años del gobierno de Raúl Alfonsín para luego adentrarnos en el análisis de las formas que la picaresca adquirió en su paso al video hogareño y los vínculos que estableció con otras producciones cómicas en video.

\section{Situación de la industria audiovisual durante el gobierno de Raúl Alfonsín}

Hacia fines de la década del ochenta el gobierno de Raúl Alfonsín atravesaba una crisis institucional grave, fundamentalmente debido al fracaso de los diversos planes económicos que la administración radical implementó sin éxito. Durante 1989, el último año de su 
gestión, se profundizó la inestabilidad económica, debido a una serie de picos hiperinflacionarios, es decir una gigantesca escalada de precios, que provocó una devaluación en el poder adquisitivo de la población empobreciendo a gran parte de las clases medias y bajas (Gerchunoff y Llach, 1998). Esta situación afectó profundamente a la industria cinematográfica local dado que el constante aumento de precios dificultaba tanto la producción de películas como la distribución y la recaudación. Durante la gestión de Manuel Antín al frente del Instituto Nacional de Cine, que duró todo el gobierno de Alfonsín, el cine argentino había mostrado signos de recuperación. A partir de 1989 en cambio, la producción de largometrajes comenzó a caer provocando también una reducción en la cantidad de estrenos nacionales. ${ }^{3}$ A su vez, la crisis económica produjo una baja en la asistencia a las salas cinematográficas por parte del público de clase media y media baja que, ante la imposibilidad de afrontar el precio de una entrada de cine, redireccionó sus consumos culturales hacia otras ofertas audiovisuales que comenzaban a ganar terreno (Getino, 1995, 122). Entre ellas se destacó el video hogareño.

Entre las principales innovaciones tecnológicas que se dieron durante la primera mitad de la década del ochenta se encuentra la aparición de la videocasetera. En un principio fue un consumo de lujo, introducido por las clases medias porteñas que, gracias a la política cambiaria aplicada por el ministro de economía José Martínez de Hoz, pudieron comprar tecnología barata en sus viajes al exterior. Pero hacia fines de los ochenta se fue masificando. A medida que aumentó el parque de videocaseteras las urbes se poblaron de videoclubes -negocios de compra, venta y alquiler de VHSque fueron creciendo y diversificándose por el territorio argentino hasta que, al igual que otros negocios de moda, desaparecieron cuando el público centró su atención en un nuevo tipo de consumo. Pero durante

3 Entre 1989 y 1994 el promedio de estrenos cayó abruptamente en relación al período 1983-1989. Se pasó de un promedio de 22 títulos anuales a uno de 12. Con respecto a la cantidad de espectadores se pasó de 63 millones en 1984 a 19 millones en 1995 (Getino, 1995, 177). casi dos décadas fueron un negocio muy redituable. ${ }^{4}$ Las revistas de la época registraron el crecimiento del rubro, publicaron entrevistas a dueños que hablaban de expandirse, a editores que contaban entusiasmados los próximos lanzamientos, y a consumidores que comentaban cuáles eran sus preferencias. ${ }^{5}$

A diferencia de la oferta brindada por la televisión abierta y por el cable, ${ }^{6}$ los videoclubes ofrecían a sus socios una diversidad de material audiovisual mucho mayor. Los catálogos, a medida que la industria editora crecía, se volvieron amplios y diversos creando la posibilidad de la apertura de videoclubs especializados para el espectador exquisito. A su vez los kioscos de diarios y revistas comercializaban una gran cantidad de títulos en video que acompañaban a diversas publicaciones, que iban desde documentales sobre la fauna local hasta material condicionado, lo que permitía que el público fuera construyendo, a partir de sus preferencias, una videoteca propia. Como señala Oscar Landi (178), la masificación del video permitió a los videoclubes cumplir una función favorable en la difusión de películas para un público que tenía un vínculo escaso con el cine.

4 De acuerdo a Octavio Getino $(1995,245)$ en la segunda mitad de la década del ochenta se produjo un crecimiento exponencial de locales de alquiler de videocasetes que se mantuvo durante los primeros años de la década del noventa. El país pasó de tener 500 videoclubes habilitados en 1986 a tener 7000 en 1993 . A su vez, Susana Velleggia $(1990,53)$ señala que para 1989 la venta de películas en video por parte de las video editoras a los videoclubes ascendía a 40 millones de dólares y la sumatoria de todos los alquileres del país arrojaba una cifra de 100 millones de dólares. Es necesario señalar que el crecimiento de la TV por cable afectó profundamente la comercialización de VHS. Para 1996, de los 7000 videoclubes que había tres años antes, solo quedaban 3300. Entre 1992 y 1996 se produjo un descenso tanto del número de películas editadas como alquiladas (Getino, 1995, 215).

A mediados de los ochenta surgieron varias revistas que se ocuparon de cubrir el campo del video. Se destacan las publicaciones Video para usted, Video Club, Prensario del video y Video News.

De acuerdo a Ulanovsky, Itkin y Sirvén $(1999,503)$ los comienzos de la televisión por cable, en la Argentina, pueden remontarse a comienzos de la década del sesenta. Empezó siendo una alternativa para aquellos lugares, alejados de los centros urbanos más populosos, a donde la televisión de aire no llegaba. Para comienzos de la década del ochenta, dos empresas locales (Cablevisión y Video Cable Comunicación) comienzan a expandir el negocio con el fin de desembarcar en la Capital Federal y competir con la televisión de aire. En 1986 se autoriza la recepción de señales satelitales lo que le permite a las empresas prestadores de cable diversificar su programación y volverla más atractiva para el público de clase media porteño. El principal atractivo de la programación era la variedad de material audiovisual (cine y series) lo que convirtió a este servicio en un competidor de la televisión por aire, las salas de cine y los videoclubes. En 1987 el número de abonados en todo el país era alrededor de 900 mil. Este fue creciendo a lo largo de la década del noventa, gracias a las políticas reguladoras que aplicó el gobierno de Carlos Menem, llegando a ser de 4.7 millones en 1996 (217). 
Otra ventaja del video sobre el cine era que otorgaba la posibilidad de consumir imágenes en movimiento en la soledad del hogar en el momento en el que los socios lo desearan, a diferencia de los cines que promovían el visionado en espacios compartidos y con horarios impuestos por los exhibidores. Poco a poco el consumo en el hogar se impuso.

A medida que el mercado se desarrollaba y el video se convertía en un objeto de consumo redituable, muchos productores ávidos de incrementar sus ganancias vieron un espacio favorable, no solo para la edición de material nacional o extranjero, sino también para la producción de material realizado exclusivamente para ser consumido en el hogar. La inversión requerida para realizar un video de bajo presupuesto era diez veces inferior a la necesaria para realizar una película en fílmico. El gasto de producción era escaso y la posibilidad de que el mismo video fuera alquilado por muchas personas hacía que la producción de películas para el hogar fuera una actividad potencialmente redituable (Getino, 1995, 216). Esto hizo que muchas editoras independientes comenzaran a realizar películas en este soporte con el fin de ampliar el espectro de su negocio. Para que este resultara fructífero era necesario que el material producido fuera atractivo para el público de los videoclubes. Es por ello que a la hora de lanzarse a producir decidieron incursionar en el ámbito de lo cómico, un tipo de producción muy popular en el video.

\section{La comicidad popular llega al video}

Antes de adentrarnos en el análisis de la picaresca en video consideramos necesario ahondar en el campo de lo cómico producido para el mercado audiovisual hogareño dado que entendemos que las distintas producciones que fueron diseñadas para ser comercializadas en este dispositivo prepararon el terreno para el desembarco de la comedia para adultos a este nuevo ámbito.

Velleggia (1990, 53-54) señala que en el bienio 1987-1988 alrededor del $20 \%$ de lo editado eran clasificado por las editoras como comedias.
Entre los formatos desarrollados podemos mencionar, en primer lugar, los registros en vivo de una serie de obras pertenecientes a lo que Osvaldo Pellettieri (227) denominó circuito del «Teatro de la calle Corrientes», el cual incursionaba, en general, en la comedia de raigambre popular y tenía por protagonistas a figuras popularizadas por la televisión. Muchos de estos shows fueron escritos, dirigidos y protagonizados por artistas que se destacaron en la comedia sexual, entre ellos Jorge Porcel, uno de los comediantes más populares en su versión cinematográfica y televisiva. La buena recaudación en boletería y la popularidad de los protagonistas resultaron atractivos suficientes para las incipientes productoras y distribuidoras locales de video para lanzarse al registro de estas obras. La masividad de los comediantes que encabezaban estos shows garantizó una buena recepción para los videos, lo que a su vez permitió que las productoras pensaran en desarrollar otro tipo de producciones audiovisuales dentro del campo de lo cómico.

Al segundo tipo de material lo denominaron video concert. Este consistió en el registro de la performance de diversos cómicos populares realizados especialmente para el campo del video. No son registros de una función de una obra teatral sino más bien una recreación de una puesta teatral (Sánchez Noriega, 73). En distintas notas periodísticas, en donde se abordó el fenómeno del video concert, se señala que estos shows cómicos tienen la particularidad de no haber sido concebidos ni como espectáculos teatrales ni como programas de televisión sino como productos únicos que mezclaban elementos del café concert ${ }^{8}$ y recursos del mundo televisivo. ${ }^{9}$ Estos comentarios permiten pensar que el video, como nuevo espacio de producción, era considerado por el periodismo, aunque también por editores, productores

8 El café concert surgió en Argentina a mediados de la década del 60 de la mano de un conjunto de jóvenes artistas que buscaban realizar un teatro y un humor diferente al que imperaba en la escena nacional. Se instalaron en espacios alternativos a los teatros más populares de la época, espacios pequeños que generaban una comunidad con el público que asistía. Practicaron un humor mordaz contra los discursos legitimados por la sociedad, contra la moral de la clase media y contra la política nacional. En estos espectáculos se mezclaban monólogos, sketchs humorísticos y canciones. Podían ser tanto unipersonales como realizados por un elenco reducido (Sanz, 2011).

s/f (1988), «El boom del video concert», Video para usted $\mathrm{n}^{\circ} 19$, diciembre 1988. 
y realizadores como un medio más cercano a la televisión antes que al cine. Es decir que estos videos no se limitaron a registrar la performance del cómico sino que llevaron a cabo una adaptación pensando en que el espectador ideal era un televidente, alguien acostumbrado a ver programas de televisión antes que teatro. Sin embargo, no dejaron de tener elementos del mundo teatral (un escenario en donde transcurre la acción, una interpretación teatral por parte del cómico, la presencia de público durante la función, la interacción del comediante con la audiencia). Por lo tanto, la puesta puede ser pensada como el resultado de la hibridación de elementos formales de ambos medios, como un producto intermedial.

La decisión de emparentar los videos a la televisión puede explicarse por diversas razones. Por un lado, los video concerts eran productos audiovisuales pensados para ser vistos en la privacidad del hogar y no en espacios públicos como los cines; su destino era ser reproducido en un televisor. Por otro lado, la televisión local, y el periodismo especializado, estaba familiarizada con el video hacía tiempo. Los canales lo adoptaron en 1960 como soporte para grabar sus programas cuando las emisoras, públicas y privadas, dejaron de priorizar la transmisión en vivo de sus programas (Varela, 2015, 119). A mediados de los setenta, gracias a las innovaciones de las cámaras, el video fue incorporado como una herramienta novedosa por diversos programas periodísticos lo que familiarizó al público con este tipo de tecnología (Barbarena, 18). ${ }^{10}$ Para la década del ochenta este soporte se había vuelto de uso común en la televisión local.

Hacia fines de la década del ochenta las estanterías de los videoclubes se poblaron con estos shows cómicos. Revistas especializadas llegaron a hablar del «boom del video concert $\rangle^{11}$. Luego de este pico de éxito el interés del público mermó, por lo que finalmente desapareció. A pesar de su corta vida, fueron un producto importante tanto para quienes trabajaban dentro del campo

\footnotetext{
Entre ellos podemos mencionar al programa Videoshow cuya popularidad fue en parte gracias a las notas realizadas en formato video desde lugares remotos.

1 s/f (1988), «El boom del video concert», Video para usted $\mathrm{n}^{\circ} 19$, diciembre 1988.
}

del humor como para las productoras y editoras. En lo que respecta a los comediantes fue un espacio propicio para que figuras consagradas y emergentes, tanto del café concert como de la televisión, pudieran difundir su trabajo. ${ }^{12}$ Para los productores fueron una forma de obtener ganancias, por alquiler y venta de casetes, pero también un antecedente importante a partir del cual pensaron el pasaje de la comedia picaresca al video. Su concepción sobre el video como un dispositivo intermedial, cercano a la televisión, fue luego retomada por aquellos que pensaron la nueva versión de este modo cómico.

\section{Picaresca directo a video}

La comedia picaresca fue durante casi dos décadas una de las producciones culturales más populares del campo audiovisual argentino. Sus comienzos pueden remontarse a la década del sesenta con las películas de hoteles alojamientos que, producto de la modernización del campo cultural y de los cambios producidos en las costumbres y los consumos de la clase media porteña, llevaron a la pantalla grande las inquietudes sexuales de dicha clase. Estas películas lograron construir una fórmula -comicidad centrada en lo erótico y lo sexual, elencos integrados por figuras popularizadas de diversos ámbitos, presencia de mujeres con poca ropa para disfrute del espectador masculino- que fue luego repetida y reformulada a lo largo de los años por diversas figuras cómicas (Valdez, 2005). ${ }^{13}$ Cerrado este primer ciclo, comenzó a mediados de los setenta, un nuevo ciclo de comedias picarescas de la mano de dos de sus máximas estrellas, Alberto Olmedo y Jorge Porcel. Estas narraron las desventuras de dos amigos que, aburridos de su vida rutinaria y obsesionados con el

El video concert fue un espacio diverso en el cual convivieron una diversidad de comediantes. El café concert aportó nombres como los de Carlos Perciavalle, Edda Díaz y Enrique Pinti. El teatro de revistas a José Marrone y Juan Verdaguer. La televisión a Jorge Corona, que fue uno de los más exitosos en este terreno. Entre 1987 y 1996 realizó once videos.

13 Se destacan, entre otras, La cigarra no es un bicho (Daniel Tinayre, 1963), la película que da inicio al ciclo, y Hotel alojamiento (Fernando Ayala, 1966). 
sexo, recorrían las calles de la ciudad intentando conquistar mujeres. ${ }^{14}$ Dada su popularidad, este modelo logró convertirse, por más de una década, en un modelo cómico hegemónico (D’Antonio, 2015). Sin embargo, hacia fines de la década del ochenta y principios de los noventa, producto de cambios culturales y de transformaciones en el campo audiovisual local, desaparecieron de las salas de cine. ${ }^{15}$

Como señalamos en la introducción, este subgénero, lejos de desaparecer, encontró refugio en el campo del video. Se produjo el cierre de un ciclo, el de la picaresca cinematográfica, para dar comienzo a uno nuevo, el de la picaresca en video. Siguiendo a Altman (2000), entendemos que este nuevo momento de la comedia sexual retomó elementos del momento previo y los reformuló pensando en el nuevo campo. Esto es lo que hizo que en su desembarco en el video la comedia picaresca sufriera una serie de modificaciones. El entramado intermedial en el cual este modo cómico estaba inserto, a la vez que el incipiente mundo del video, sirvieron como fuentes de recursos para reformular elementos y otorgarle una nueva forma a la comedia picaresca.

Uno de los primeros en realizar comedias en el ámbito del video fue el productor y distribuidor Juan Carlos Muruzeta, que muy tempranamente produjo la película Esto es vida (Fernando Siro, 1982) con el fin de ampliarla a $35 \mathrm{~mm}$ y estrenarla en salas cinematográficas. Lamentablemente no pudo cumplir con su objetivo por lo que la película permanece aún inédita (Manrupe y Portela, 213). Cuando Muruzeta intentó adentrarse en el campo del video todo era muy nuevo e inestable. No había ninguna garantía de poder recuperar lo invertido. Hacia fines de los ochenta la situación era distinta.

\footnotetext{
14 Podemos mencionar, entre otras, Los caballeros de la cama redonda (Gerardo Sofovich, 1973), que inicia la saga, Los hombres piensan solo en eso (Enrique Cahen Salaberry, 1976) y Las mujeres son cosas de guapos (Hugo Sofovich, 1981). En los años ochenta se destacan las películas del cómico Tristán entre las que se encuentra Camarero nocturno (Gerardo Sofovich, 1986).

La última película del género, Enfermero de día, camarero de noche (Aníbal Di Salvo), se estrena en 1991. No se vuelven a realizar largometrajes de este tipo hasta 1997 cuando Hugo Sofovich filma La herencia del tío Pepe. Esta película fue un fracaso de taquilla. El público ya no respondía ante este tipo de producciones aunque si lo hacía ante productos televisivos en los que Sofovich explotaba el mismo humor.
}

La venta de videocaseteras crecía, los videoclubes se expandían y los catálogos se ampliaban. En este contexto editoras como Arrakis (de Roberto Sena) o Buena Onda Home Video (de Pablo Bellini), y más tarde productoras como Pictoris cinematográfica (de Héctor Bailez), se lanzaron a realizar películas. A diferencia de Muruzeta que había optado por la comedia costumbrista, Sena, Bellini y Bailez se adentraron en el mundo del humor adulto elaborando una reversión del cine picaresco acorde al presupuesto que manejaban. De los tres, el más experimentado era Bailez, que hacía más de treinta años que se dedicaba a la producción, y que conocía el género al haberlo abordado en los años en los que estuvo al frente de Cinematográfica Victoria. ${ }^{16}$ Sena y Bellini no habían filmado previamente pero conocían el negocio de la distribución y comercialización. A pesar de las diversas trayectorias los tres tenían un mismo objetivo: realizar películas que resultaran atractivas para el público de la picaresca pero con un presupuesto reducido. El propósito de estos productores era ampliar las fronteras de la explotación comercial de un modo cómico cuya popularidad todavía gozaba de buena salud.

En su formato cinematográfico las comedias picarescas siempre fueron producciones de bajo presupuesto realizadas velozmente. Esta característica se vio redoblada en su paso al video en donde se produjo un cambio en los ritmos de producción. De ser filmadas en un promedio de cuatro semanas pasaron a ser hechas a contrarreloj en jornadas extensas de pocos días. Cuantos menos días de rodaje implicara el rodaje menos costosa resultaba la producción del video. La necesidad de reducir costos, producto de la compleja situación económica que atravesaba el país, llevó a los realizadores a poner en práctica un tipo de puesta en escena sin riesgos, cercana a la de los programas de ficción cómica que poblaban la televisión en el período. ${ }^{17}$

\footnotetext{
${ }^{16}$ Cinematográfica Victoria S.R.L. fue creada a comienzos de los años setenta por Héctor Bailez que venía del negocio de la exhibición. Entre 1969 y 1990 produjo 29 películas que van desde la comedia familiar al cine testimonial aunque también por la picaresca. Luego de presentar la quiebra, Bailez armó Pictoris cinematográfica S.A. que produjo una serie de películas directo a video.

La crisis del país afectó profundamente el proyecto de las productoras de video.
} 
Incluso aquellas producciones que fueron dirigidas por directores con amplia experiencia en el cine, como Carlos Galettini o Emilio Vieyra, fueron pensadas para un espectador de televisión antes que para el público del cine.

Diversos elementos son los que emparentan estas comedias al formato televisivo. Serge Daney (125) define a la televisión como el reino del campo único, como un tipo de imagen en donde el fuera de campo parece no existir. En los programas televisivos toda la acción sucede dentro del cuadro y está concentrada en su centro. La cámara permanece, en general, fija y los movimientos que realiza se limitan al reencuadre por medio del zoom. Pierre Sorlin (204), por su parte, señala que la televisión, por motivos económicos, se caracterizó por recurrir a tomas de larga duración y por evitar la fragmentación de una escena en planos. Cuantas menos tomas se hacen, menos tiempo se usa la sala de montaje y por lo tanto se gasta menos dinero. Todo lo señalado por Daney y Sorlin podemos encontrarlo en las comedias directo a video. Tomemos como ejemplo la escena del bar, entre el camarero y el cliente en Maestro de pala (Emilio Vieyra, 1993). Como la comicidad gira en torno a la torpeza del mozo, para que esta sea apreciada, Vieyra encuadra toda la escena por medio de un plano general que permite ver los movimientos del cómico. Sin embargo, como toda la interacción entre ambos personajes está encuadrada por medio del mismo plano las reacciones del comensal ante las acciones cómicas del protagonista no pueden apreciarse haciendo que lo reidero pierda parte de su efecto. Estas decisiones de puesta repercutieron en el tipo de comicidad que los comediantes se vieron habilitados de practicar.

En declaraciones a la revista Video para usted, a raíz del lanzamiento de Más loco que un crucero (1989), Roberto Sena afirmaba que esta comedia formaba parte de un proyecto más ambicioso que implicaba la realización de cuatro películas con alto presupuesto para ser distribuida en el mercado internacional. Sin embargo, no pudo cumplir con sus propósitos en sus siguientes películas. De alquilar un crucero de lujo y filmar en exteriores en distintas ciudades del Uruguay, Sena pasó a ambientar sus películas en los interiores de un hotel alojamiento de baja categoría. Un caso extremo de esta situación es la corta obra de Alfredo Lepore que dirigió, escribió y protagonizó dos comedias para el campo del video. Ambas fueron filmadas en un solo espacio, un estudio que simulaba ser el living de un departamento, que funcionaba como el lugar en donde se sucedían los conflictos de los matrimonios que estelarizaron ambos vodeviles.
Esto los llevó a descartar el trabajo con la imagen y a recurrir al humor verbal. Se le dio tal primacía a los diálogos que el sentido quedó ligado a la palabra (Sorlin, 209). Si bien no hay cabezas parlantes, porque la utilización de primeros planos es reducida, sí encontramos cuerpos parlantes. Cuerpos que hablan más de lo que hacen. En estos videos la palabra está por encima de la acción. ${ }^{18}$

El uso de la palabra que se puede apreciar en estas comedias es opuesto al que realizaba la picaresca cinematográfica. Este tipo de comedia tuvo siempre un fuerte contenido sexual. La comicidad se sostenía, en gran parte, sobre chistes que hacían referencia al sexo. La risa era provocada por el uso que los actores hacían de lo no dicho, de lo sugerido, de eufemismos creativos que les permitían hablar de aquello que la censura consideraba inmoral. Un uso del lenguaje que tiene profundas raíces en tradiciones de la cultura popular. En palabras de Martín-Barbero (75) era:

un lenguaje en el que predominan, en el vocabulario y los ademanes, las expresiones ambiguas, ambivalentes, que no sólo acumulan y dan salida a lo prohibido, sino que al operar como parodia, como degradación- regeneración, contribuían a la creación de una atmósfera de libertad.

La picaresca se caracterizó entonces por un uso lúdico del lenguaje, es decir por la creación de juegos de palabras que recurren a la multiplicidad de significados que un significante puede despertar y que requiere de la capacidad del espectador para interpretar rápidamente estas reorientaciones del sentido (Ortiz, 2014). En su paso al video este uso del lenguaje se transformó y lo que antes era sugerido de forma creativa pasó a estar explicitado. Desaparecieron las metáforas sexuales dando lugar a la grosería y el insulto.

Podemos ver un ejemplo de ello en la película para video Experto en ortología (Andrés Redondo, 1991) que, ya desde su título, realiza un juego de palabras que recurre a la homofonía y el equívoco. El protagonista

\footnotetext{
18 Otro elemento que emparenta estos videos con los programas cómicos es la duración. Duran entre 50 minutos y una hora veinte, una duración similar a la que tenían las telecomedias y los programas cómicos.
} 
de esta comedia es un médico especializado en «ortología». Asistimos entonces a una situación dentro del terreno del absurdo dado que la ortología es una rama de la lingüística y no de la medicina. A lo largo del filme veremos que este es en realidad un proctólogo. Por lo tanto, no es un especialista en la pronunciación correcta de las palabras sino un experto en ortos, argentinismo vulgar para referirse a las nalgas de una persona. Al comienzo de la comedia vemos como el cómico lleva a cabo la defensa de su tesis doctoral, que no versa sobre una parte del cuerpo sino sobre el uso en el lenguaje cotidiano de palabras referidas al cuerpo. Toda la disertación está construida sobre juegos de palabras que, lejos de sugerir, recurren al uso de términos que el buen gusto prohíbe. Así como la puesta acerca a la picaresca a la televisión, el uso de groserías e insultos la aleja. Si bien este medio, producto del fin de la censura que había imperado en dictadura y del «destape culturab» ${ }^{19}$ que imperó en los ochenta, se había vuelto más permisivo todavía seguía siendo un espacio controlado. El video, en cambio, permitía otras libertades. La grosería y la explotación del sexo podían abordarse de otra forma. No en vano, muchos de estas comedias eran publicitadas con el eslogan «lo que no se puede ver en televisión».

La concepción del video, como un campo cercano a la televisión, antes que al cine, también fue compartida por varios realizadores y productores del campo televisivo que lo entendieron como un espacio propicio para continuar con la explotación de sus productos. Jorge Porcel, quien hacia fines de los ochenta había abandonado el cine para concentrarse en el teatro y la

Entendemos por «destape» a la explosión de manifestaciones artísticas y culturales que abordaron de manera desprejuiciada, para los cánones de la época, asuntos del mundo de la política, de la economía y de la cultura a partir de 1983, con la vuelta de la democracia y como resultado de la eliminación de la censura. El término fue impulsado por la prensa local que vio en la transformación que experimentó la sociedad española, una vez terminado el franquismo, un modelo a partir del cual leer lo que acontecía en la Argentina de los años ochenta (Manzano, 2019, 139). Uno de los temas que más explotaron las obras del «destape» fue el sexo, en particular aquellas pertenecientes al ámbito de lo popular-masivo como el cine, la televisión o el humor gráfico. Como señala Mariana Milanesio $(2019,93)$ se produjo «una avalancha de imágenes sexuales y de narrativas que se caracterizaron por alcanzar nuevos niveles de explicitación visual y discursiva sobre el sexo y el cuerpo, tópicos que la dictadura había considerado de mal gusto, inmorales, incontrolables y, por todas esas razones, peligrosos». televisión, realizó dos especiales para el mundo del video hogareño. En ambos optó por reproducir la puesta que llevaba adelante en sus sketchs televisivos para lo que contrató a Wilfredo Ferrán, el director de cámaras de sus programas, ${ }^{20}$ y a Fernando Siro, director y actor con experiencia tanto en cine como en televisión. En ellos podemos encontrar una serie de elementos propios de lo que Damián Fraticelli (2013) denomina neo-humor televisivo. En este tipo de programas cómicos, que emergieron en la década del ochenta, propusieron una serie de innovaciones en relación a la comicidad televisiva previa al romper con la transparencia de la enunciación televisiva y desvelar al público que está frente a una ficción. Entre los elementos característicos del neo-humor presentes en los videos de Porcel podemos mencionar la mirada cómplice a cámara por parte del capocómico, la interacción de este con los técnicos -en A la cocina con Porcel (1991) son constantes las discusiones con el director de cámaras a quien Porcel termina «asesinando»-, y la mostración del público que presencia la grabación del video -Porcel los reta ya sea por no aplaudir o por aplaudir demasiado-.

\section{Consideraciones finales}

A partir de lo expuesto podemos concluir que luego del cierre del ciclo del género picaresco cinematográfico protagonizado por Olmedo y Porcel hubo una serie de intentos por parte de la industria local por buscar nuevos caminos a través de los cuales explotar este modo cómico. Esta insistencia en la explotación del género se debió a la popularidad que las comedias de este tipo tenían entre los sectores más populares, lo que las convertía en una inversión potencialmente redituable. El video, en plena expansión, apareció entonces como un espacio favorable para continuar con su desarrollo.

Si bien, hacia fines de los ochenta el mercado del video crecía, todavía no existía una producción local bien establecida. Existían apenas unas pocas producciones

\footnotetext{
20 Nos referimos a Las gatitas y los ratones de Porcel (1987-1990) y Las bebitas y bebotes de Porcel (1990)
} 
entre las cuales se destacó el video concert. Este producto audiovisual fue importante para el desarrollo del nuevo ciclo de la picaresca en tanto preparó el terreno para su explotación. Estos shows cómicos instalaron al humor local como un objeto posible de ser explotado en el campo del video. A su vez su concepción del video como un dispositivo televisivo antes que cinematográfico fue luego retomada por los productores que se lanzaron a realizar comedias picarescas.

Los productores emergentes (Sena, Bellini, Bailez) no vieron en el video un nuevo dispositivo cuyas posibilidades expresivas explotar sino, por el contrario, un medio para continuar desarrollando formatos audiovisuales estandarizados provenientes del cine y de la televisión que habían agotado su vida comercial. Este nuevo ciclo de la picaresca estableció vínculos intermediales distintos a los que el ciclo previo había desarrollado. El iniciado por Olmedo y Porcel se caracterizó por sus vínculos con el teatro de revistas y el vodevil, en cambio el nuevo, si bien mantuvo relaciones con diversos ámbitos - con el video concert entre otros-, desarrolló un fuerte lazo con la televisión, en particular con los programas cómicos televisivos. Este último ciclo, aunque apuntó a un espectador televisivo antes que cinematográfico, no dejó de explotar narrativas y temas propios de este modo cómico. Continúo haciendo uso de un humor centrado en lo sexual, recuperó espacios tradicionales de este tipo de comicidad como lo eran los hoteles alojamiento y siguió teniendo una fuerte presencia de desnudos femeninos. Sin embargo, el acercamiento a la televisión reconfiguró a la picaresca transformado su puesta en escena y con ella los recursos cómicos explotados por sus estrellas. Podemos concluir que este pasaje a un nuevo dispositivo permitió continuar con la explotación, por un tiempo acotado, de este modo pero a la vez implicó una transformación del mismo que repercutió en su identidad. Los realizadores llevaron adelante una estrategia por medio de la cual la acercaron a la televisión al mismo tiempo que buscaron diferenciarse de este medio con el fin de no perder su esencia.

\section{Bibliografía}

Altman, Rick. Los géneros cinematográficos. Barcelona: Paidós, 2000.

Barbarena, Martín. La inserción del video en el ámbito doméstico y su incidencia en el desarrollo de la cultura audiovisual. Facultad de periodismo y comunicación social-Universidad Nacional de La Plata (Tesis), 2010. MIMEO.

Camarero, Emma. «De lo banal a lo indispensable. Pornochachada y Cinema Novo durante la dictadura brasileña (1964-1985)». L'Atalante. Revista de estudios cinematográficos, 23, 2017, pp. 95-108.

Daney, Serge. «Como todas las viejas parejas, el cine y la televisión terminan por parecerse». Cine, arte del presente, Buenos Aires: Santiago Arcos, 2004, pp. 125-129.

D'Antonio, Deborah. «Paradojas del género y la sexualidad en la filmografía durante la última dictadura militar argentina». Revista Estudios feministas, 23 (3), 2015, pp. 913-937.

Fraticelli, Damián. «Una periodización de los programas cómicos: Paleo, Neo y Humor Post-televisivo». Imagofagia, 8, 2013, pp. 1-19, http://www.asaeca. org/imagofagia/index.php/imagofagia/article/ view/421 Recuperado el 1 de octubre de 2020.

Galuppo, Gustavo. «Video, el cine por otros medios». Comps. Jorge La Ferla y Sofía Reynal, Sofía (Comp.). Territorios audiovisuales. Buenos Aires: Libraria, 2012.

Gerchunoff, Pablo y Lucas Llach. El ciclo de la ilusión y el desencanto. Buenos Aires: Ariel, 1998.

Getino, Octavio. Las industrias culturales en la Argentina: dimensión económica y políticas públicas. Buenos Aires: Colihue, 1995.

- Cine argentino. Entre lo posible y lo deseable. Buenos Aires: Ciccus, 1998.

Kessler, Cristina. «Erotismo à brasilera: o ciclo da pornochachada». Sessões do imaginario, 22, 2009, pp. 14-20.

King, Geoff. Film comedy. Nueva York: Wall Flower Press, 2002.

Landi, Oscar. Devórame otra vez. Buenos Aires: Editorial Planeta, 1992. 
Lemus Martínez, Violeta. «Erotismo, sexualidad e iconografía en el cine mexicano de Ficheras de los años 1970». América. Cabiers du CRICCAL, 46, 2015, pp. 161-168.

Manzano, Valeria. «Tiempos de destape: sexo, cultura y política en la Argentina de los ochenta». Mora, 25, 2019, pp. 135-154, https://doi.org/10.34096/mora. n25.8526 Recuperado el 1 de octubre de 2020.

Manrupe, Raúl y Alejandra Portela. Un diccionario de filmes argentinos (1930-1995). Buenos Aires: Corregidor, 2001.

Martín-Barbero, Jesús. De los medios a las mediaciones. Barcelona: Gustavo Gili, 1987.

Milanesio, Natalia. «Sex and Democracy: The Meanings of the Destape in Postdictatorial Argentina». Hispanic American Historical Review, 99 (1), 2019, pp. 91-122, https://doi.org/10.1215/00182168-7287984 Recuperado el 1 de octubre de 2020.

Ortiz, María Florencia. «Juegos de palabras». Coord. Ana Flores. Diccionario crítico de términos del bumory breve enciclopedia de la cultura humorística argentina. Córdoba: Universidad Nacional de Córdoba, 2014, pp. 99-108.

Pellettieri, Osvaldo. «Remanencia del sistema premoderno». Ed. Osvaldo Pellettieri. Historia del teatro argentino en Buenos Aires. Volumen V: el teatro actual (1976-1998). Buenos Aires: Galerna, 2001,pp. 227-255.

Rajewsky, Irina. «Intermediality, intertextuality and remediation: a literary perspective on intermediality» Intermédialités, 6, 2005, pp. 43-64.
Ramírez Ferreiro, Jesús. «¿La industria inexistente? ("cine de ficheras" en los ochenta)». Navegando, 6, 2017, pp.4-14.

Sanz, María de los Ángeles. «Historia del café-concert en Buenos Aires. De la música al humor». Teatro y representación. Ed. Roger Mirza, Editor. Montevideo: Universidad de la República, 2011.

s/f. «Aquí podemos hacerlo». Video para usted, 31, 1989.

s/f. «El boom del video concert». Video para usted, 19, 1988.

s/f .«Perciavalle con todo». Video Club, 27, 1985.

Sánchez Noriega, José Luis, De la literatura al cine. Teoría y análisis de la adaptación. Barcelona: Paidós, 2000.

Sorlin, Pierre. Estéticas del audiovisual. Buenos Aires: La Marca, 2010.

Ulanovsky, Carlos, Silvia Itkin y Pablo Sirvén. Estamos en el aire. Una historia de la televisión en la Argentina. Buenos Aires: Planeta, 1999.

Valdez, María. «Sábanas para el amor: el cine de hoteles». Cine argentino. Modernidad y Vanguardias. 1957/1983. Vol. I. Dir. Claudio España. Buenos Aires: Fondo Nacional de las Artes, 2005, pp. 256-257.

Varela, Mirta. La televisión criolla. Desde sus inicios hasta la llegada del hombre a la Luna (1951-1969). Buenos Aires: Edhasa, 2015.

Velleggia, Susana. Cine y espacio audiovisual argentino. Buenos Aires: Instituto Nacional de Cinematografía, 1990. 
